\title{
Corrigendum: Hypoxia-inducible factor-dependent induction of netrin-1 dampens inflammation caused by hypoxia
}

Peter Rosenberger, Jan M Schwab, Valbona Mirakaj, Eva Masekowsky, Alice Mager, Julio C Morote-Garcia, Klaus Unertl \& Holger K Eltzschig Nat. Immunol. 1, 195-202 (2009); published online 4 January 2009; corrected after print 27 February 2015

In the version of this article initially published, the contrast in lane 4 of Figure $2 \mathrm{c}$ had been altered, and the top right image in Figure $5 \mathrm{a}$ and bottom right image Figure 6e were incorrect. The correct gel and images are now presented. The error has been corrected in the HTML and PDF versions of the article.

\section{Corrigendum: A new class of highly potent, broadly neutralizing antibodies isolated from viremic patients infected with dengue virus}

Wanwisa Dejnirattisai, Wiyada Wongwiwat, Sunpetchuda Supasa, Xiaokang Zhang, Xinghong Dai, Alexander Rouvinsky, Amonrat Jumnainsong, Carolyn Edwards, Nguyen Than Ha Quyen, Thaneeya Duangchinda, Jonathan M Grimes, Wen-Yang Tsai, Chih-Yun Lai, Wei-Kung Wang, Prida Malasit, Jeremy Farrar, Cameron P Simmons, Z Hong Zhou, Felix A Rey, Juthathip Mongkolsapaya \& Gavin R Screaton

Nat. Immunol. 16, 170-177 (2015); published online 15 December 2014; corrected after print 27 February 2015

In the version of this article initially published, the sixth author's surname is spelled incorrectly. The correct spelling is Rouvinski. The error has been corrected in the HTML and PDF versions of the article.

\section{Erratum: The endothelial protein PLVAP in lymphatics controls the entry of lymphocytes and antigens into lymph nodes}

Pia Rantakari, Kaisa Auvinen, Norma Jäppinen, Maria Kapraali, Joona Valtonen, Marika Karikoski, Heidi Gerke, Imtiaz Iftakhar-E-Khuda, Johannes Keuschnigg, Eiji Umemoto, Kazuo Tohya, Masayuki Miyasaka, Kati Elima, Sirpa Jalkanen \& Marko Salmi Nat. Immunol. 16, 386-396 (2015); published online 9 February 2015; corrected after print 20 March 2015

In the version of this article initially published, the gray box in the key in the left graph in Figure 6a is labeled incorrectly. The correct label should be Plva $^{-1-}$. The error has been corrected in the HTML and PDF versions of the article.

\section{Erratum: The transcriptional regulators IRF4, BATF and IL-33 orchestrate development and maintenance of adipose tissue-resident regulatory T cells}

Ajithkumar Vasanthakumar, Kazuyo Moro, Annie Xin, Yang Liao, Renee Gloury, Shimpei Kawamoto, Sidonia Fagarasan, Lisa A Mielke, Shoukat Afshar-Sterle, Seth L Masters, Susumu Nakae, Hirohisa Saito, John M Wentworth, Peng Li, Wei Liao, Warren J Leonard, Gordon K Smyth, Wei Shi, Stephen L Nutt, Shigeo Koyasu \& Axel Kallies Nat. Immunol. 16, 276-285 (2015); published online 19 January 2015; corrected after print 8 April 2015

In the version of this article initially published, the Acknowledgments section was incomplete. The correct text should begin "We thank P. O'Brien, M. Mochizuki and N. Takeno for assistance with tissue collection...." The error has been corrected in the HTML and PDF versions of the article. 